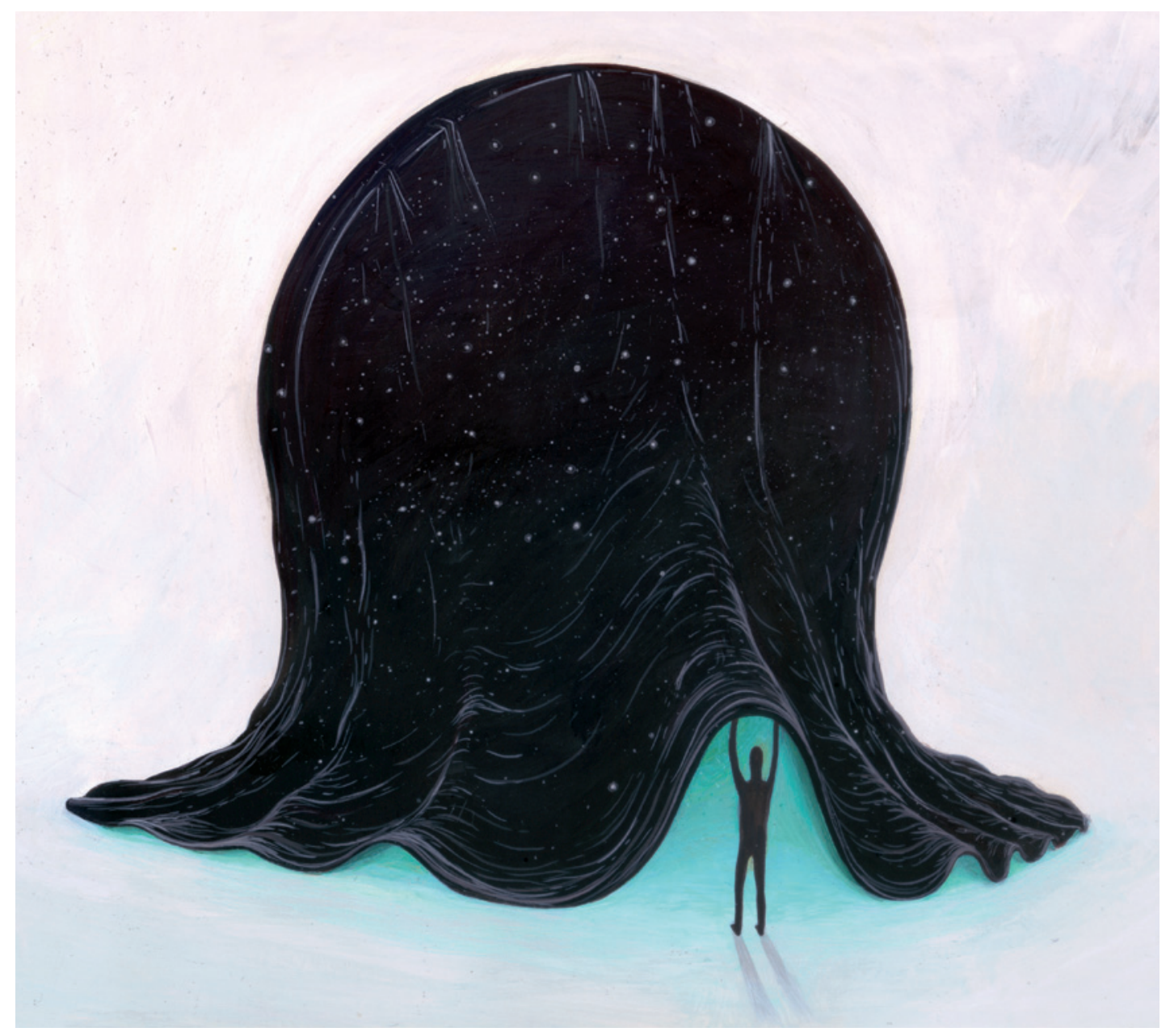

\title{
THE BIOLOGICAL HIGGS
}

\section{Biologists ponder what fundamental discoveries might match the excitement of the Higgs boson.}

\section{BY HEIDI LEDFORD}

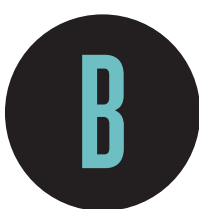

iologists may have little cause to envy physicists they generally enjoy more generous funding, more commercial interest and more popular support. But they could have been forgiven a moment of physics envy last December when, after a week of build-up and speculation, researchers at the Large Hadron Collider (LHC) near Geneva in Switzerland addressed a tense, standing-room-only auditorium.

Scientists there had caught the strongest hints yet of the Higgs boson: what some have called the 'God particle' and the final missing piece of the standard model that explains the behaviour of subatomic particles. The discovery, if confirmed, will mark the culmination of a hunt that has taken years and cost billions of dollars, and will shape the field for years to come. The research community was abuzz. "There were lots of rumours flying around about how significant the signal was," says Lisa Randall, a theoretical particle physicist at Harvard University in
Cambridge, Massachusetts, who got up at 4 a.m. to talk to the press before watching the webcast of the presentation at the LHC. "It's been quite exciting."

All this led Nature to wonder: what fundamental discoveries in biology might inspire the same thrill? We put the question to experts in various fields. Biology is no stranger to large, international collaborations with lofty goals, they pointed out — the race to sequence the human genome around the turn of the century had scientists riveted. But most biological quests lack the mathematical precision, focus and binary satisfaction of a yes-or-no answer that characterize the pursuit of the Higgs. "Most of what is important is messy, and not given to a moment when you plant a flag and crack the champagne," says Steven Hyman, a neuroscientist at the Broad Institute in Cambridge, Massachusetts.

Nevertheless, our informal survey shows that the field has no shortage of fundamental questions that could fill an anticipatory auditorium. These questions concern where and how life started — and why it ends. 


\section{IS THERE LIFE ELSEWHERE?}

In 1964, palaeontologist George Gaylord Simpson wrote a stinging dismissal of exobiology, the search for life on other planets. "This 'science' has yet to demonstrate that its subject matter exists!" he wrote ${ }^{1}$. The searing critique caused many researchers in the nascent field to shy away from exobiology.

But it was unfair, says planetary scientist Christopher Chyba of Princeton University in New Jersey. Chyba has for years been comparing the search for life on other planets to the search for the Higgs: another quest whose subject has never been proved to exist. "Why should we suddenly become giggly when it is biology at stake, rather than physics?" Chyba wrote in a 2005 rebuttal to Simpson's attack ${ }^{2}$.

The search for extraterrestrial life can be described as one way to test "a standard model of biology", says astrobiologist Chris McKay of the NASA Ames Research Center in Moffett Field, California. "It's the model of DNA and amino acids and proteins and a genetic code," he says. "It's the common features of all biology, and the framework through which everything we know about life is based." If life fundamentally different from this standard model - perhaps relying on a wildly different biochemistry - were found on another planet, it would show that there is more than one way to produce a living system, he adds.

Others say they don't need evidence of such a 'second genesis' to get a Higgs-like thrill from the prospect of life on other planets. "If we found our same biology, but on Mars, that would be pretty exciting," says biochemist Gerald Joyce of the Scripps Research Institute in La Jolla, California. "Then the question would be: where did it come from first?"

But whereas the Higgs-hunters in Geneva have a good idea of what to look for, astrobiologists seeking alternative forms of life face a bigger logistical challenge: figuring out what clues are most revealing. The chemical signatures of compounds that are commonly associated with life, such as methane or liquid water, could identify planets to focus on. But atmospheric signatures of life are unlikely to be convincing, says Chyba.

Within the Solar System, McKay puts his money on three habitats as most likely to harbour life: Enceladus, an icy moon orbiting Saturn that, according to NASA's Cassini spacecraft, probably has liquid water and is spewing organic material from cracks in its surface ${ }^{3}$; Mars, but "old Mars, not Mars today"; and Jupiter's moon, Europa, whose icy surface masks tantalizing seas of water. The Mars Science Laboratory, scheduled to land on the red planet in August, will include a simple mass spectrometer and a laser spectrometer, enabling it to detect methane, and could reveal preliminary signs of life. But the mission is not designed to yield definitive evidence.

Another way to hunt for life is to look for organic molecules that are too complex to have arisen by simple chemical synthesis, unaided by enzymes. "Let's say you came to Earth and scooped up matter," says McKay. "You'd find all of this chlorophyll and DNA: big, huge, complex molecules that were clearly there in high abundance and distinctly different from what you'd expect from a chemical mix." Finding this would require sophisticated equipment that had been baked and scrubbed free of earthly contaminants and, at present, there are no concrete plans to include such equipment on NASA's proposed trips to Mars or Europa. "My sense is that people are just trying to avoid it as long as possible," Chyba says. "Money is extremely tight, but at some point we'll just have to bite the bullet."

Searching rocks on other planets for fossils is another popular proposition, says Jeffrey Bada, a planetary geochemist at the Scripps Institution of Oceanography in La Jolla. "That's easy enough," he says. "But if you don't find them, does that tell you that life never existed there?" McKay argues that fossil evidence or living proof of life may be required to convince a field. "Ultimately, you'll have to have a body," he says. "It doesn't have to be alive, but you'll have to have a body."

\section{IS THERE FOREIGN LIFE ON EARTH?}

Alien life - and a Higgs moment - might also be lurking close to home. Some have postulated the existence of a 'shadow biosphere' on Earth, teeming with life that has gone undiscovered because scientists simply don't know where to look. It could contain life that relies on a fundamentally different biochemistry, using different forms of amino acids or even entirely novel ways of storing, replicating and executing inherited information that do not rely on DNA or proteins.

The idea is not as far-fetched as it might sound, says Steven Benner, a chemist at the Foundation for Applied Molecular Evolution in Gainesville, Florida. Researchers have found shadow biospheres before. The invention of the microscope revealed whole new worlds, says Benner; and the discovery of a new realm of microorganisms, the archaea, opened a window on another. "The question is: is it going to happen again?"

The trick is deciding what to look for and how to detect it. The usual way that researchers search for new organisms - by sequencing DNA or RNA — will not pick up life that does not depend on them.

Some scientists have speculated that desert varnish, a peculiar dark-coloured coating of unknown origin found on many desert rocks, could be a product of a shadow biosphere. Benner suggests looking in nooks and crannies that cannot support conventional life, such as areas with extremely high temperatures, radiation levels or harsh chemical environments.

Felisa Wolfe-Simon, now at the Lawrence Berkeley National Laboratory in Berkeley, California, and her colleagues took this approach when they searched for life in the arsenic-rich environment of California's Mono Lake. In late 2010, they reported the discovery of a life form that can use arsenic in place of phosphorus in its DNA and proteins - a seemingly remarkable departure from conventional life ${ }^{4}$. But at least one attempt to reproduce the result has failed.

Another approach is to search on the basis of size. If cells were liberated from their reliance on bulky ribosomes and proteins, they could be much smaller, says Benner, perhaps tucked away in rocks with pores only nanometres across. That is the rationale behind a project that John Atkins, a molecular geneticist at the University of Utah in Salt Lake City, is pursuing with Richard Herrington of the Natural History Museum in London. They plan to sequence the contents of rocks of different ages and origins with pores less than 100 nanometres in diameter. By screening for nucleic-acid sequences that lack the code for protein-making ribosomes, they hope to find a protein-free life form that has its roots in RNA, as known life probably does, but that arose independently. "The RNA world is thought to have originated, in geological terms, relatively quickly," Atkins says. "So why couldn't it have arisen again multiple times?" 


\section{HOW DID LIFE START ...?}

Even if alternative forms of life elude scientists, a fuller picture of how familiar life originated on Earth would surely create ripples in biology.

Joyce says that there will come a point at which researchers learn how to synthesize an evolving, replicating system from scratch. Getting there won't have the "monolithic, big-science march across the goal line" that has characterized the search for the Higgs, he cautions. But it will answer a key biological question: what does it take to create life from a primordial soup? And that could provide insight into how life on Earth began. "We'll never know for sure, but at least you can test plausible hypotheses," says James Collins, a synthetic biologist at Boston University in Massachusetts.

Several labs have already made headway. Joyce and his collaborators have pioneered work on the RNA-world concept, in which RNA molecules, capable of encoding information and catalysing chemical reactions, replicated and evolved faster than they degraded. RNA is notoriously unstable, and the idea is that, over time, this system gave way to DNA, a sturdier system for storing information, and proteins, a more versatile mode of catalysing reactions. "The transition to DNA and protein created the potential to evolve into more complex things," Bada says.

In 2009, a paper from Joyce's lab reported the development of a system of RNA molecules that undergo self-sustaining Darwinian evolution ${ }^{5}$. But enzymes and a human hand were needed to create the RNA sequences to start off the reaction, Joyce says, and so far his lab has not found conditions that would allow the system to form spontaneously. "We're still a bit challenged," he says. "But the system is running more and more efficiently all the time."

Jack Szostak and his colleagues at Harvard Medical School in Boston have taken a different approach, enclosing RNA molecules in fattyacid vesicles as an early step towards the creation of a primitive cell. The vesicles grow and divide spontaneously, but the genetic material does not replicate without the aid of an enzyme ${ }^{6}$.

Some believe that RNA may have had a precursor. Ramanarayanan Krishnamurthy at the Scripps Research Institute, is testing novel polymers of organic chemicals that could have formed in the primordial goo, in search of those that could replicate and evolve. "RNA was not the first living entity," says Bada. "It's too complex. Something preceded RNA, and that's where the interest is right now."

\section{... AND CAN WE DELAY ITS END?}

In a 1993 review $^{7}$, Linda Partridge and Nicholas Barton, both then researchers on ageing at the University of Edinburgh, UK, delivered "a baleful message" to the field of gerontology. The complexity of the biological networks that influence ageing, they wrote, means "it is most unlikely that engineering of a few genes or intervention in a handful of physiological pathways will prevent the process from occurring".

Things have changed. "I could tolerate that debate 20 years ago," says Richard Miller, who studies ageing at the University of Michigan in Ann Arbor. "But now it's just wrong."

Some eight months after the publication of Partridge and Barton's review, Cynthia Kenyon and her colleagues at the University of California, San Francisco, reported that mutations in a single gene allowed the nematode Caenorhabditis elegans to live more than twice as long as usual ${ }^{8}$. Three years later, a group led by Andrzej Bartke, who studies ageing at Southern Illinois University in Springfield, reported that mice bearing a single mutation that causes hormonal deficiencies live up to $68 \%$ longer than mice without the mutation'.

Both papers, and a slew of work since, have suggested that it might be possible to significantly slow human ageing and its associated diseases. Such an intervention could have a tremendous impact on society, adding years of health and economic productivity, but creating new strains on a society having to support many more older people. And scientifically, the ability to slow ageing would address Higgs-like fundamental questions about human life: why do we age; what pathways control it; and what are the consequences if they are switched off?

There are signs that such interventions may exist. In 2010, Miller and his colleagues showed that feeding mice a drug called rapamycin lengthened their average lifespan by $10 \%$ for males and $18 \%$ for females ${ }^{10}$. And slashing calorie intake by $25-40 \%$ can extend lifespan in mice and other mammals. But there is no proof that these approaches would work in humans and, even if they did, neither is likely to catch on: rapamycin can suppress the immune system, and few people can tolerate brutal dietary restriction.

One major challenge for the field is to prove that a putative lifeextending agent actually works - something that in humans would take 60 years or more. Jay Olshansky, who studies ageing at the University of Illinois in Chicago, says the field should set a concrete goal: a seven-year delay in the onset and progression of age-related disease. "If you look at the risk of most of the things that go wrong with us as we grow older, age-related risk doubles roughly every seven years," he says. "If you eliminate one doubling, you reduce the risk of everything by half. It would be monumental."

Miller has a different goal. "We will have the answer when we have something that we can put in dog food that extends the average dog's lifespan by 15 to $20 \%$," he says. Dogs offer an ideal intermediate between mice and humans, says Miller: they are considered a longlived species and live side-by-side with humans.

But Partridge and Barton's observations about the complexity of ageing still hold true. Most researchers acknowledge that they are only beginning to understand the molecular networks that regulate ageing and its associated diseases. "I don't believe there's one cause of ageing," says Brian Kennedy, president of the Buck Institute for Research on Aging in Novato, California. "But there are pathways that are designed to modulate many things at one time. I think a lot of the genes and drugs we're studying are tapping into those."

At this point, a life-extending therapy seems a much more distant prospect than does confirmation of the Higgs boson. Last month, researchers announced a bump in data from the Tevatron, the US particle collider at Fermilab in Batavia, Illinois, that is consistent with results from the LHC. It has added to physicists' excitement that they are on the threshold of discovery.

Ageing, however, "is almost the complete inverse of the situation of the Higgs particle", reflects Thomas Kirkwood, a leader in the field at Newcastle University, UK. "Everything that we're learning tells us it's highly unlikely that we'll find a single unitary cause."

Heidi Ledford writes for Nature from Cambridge, Massachusetts.

1. Simpson, G. G. Science 143, 769-775 (1964)

2. Chyba, C. F. Science 308, 495-496 (2005).

3. Postberg, F., Schmidt, J., Hillier, J., Kempf, S. \& Srama, R. Nature 474, 620-622 (2011).

4. Wolfe-Simon, F. et al. Science 332, 1163-1166 (2011)

5. Lincoln, T. A. \& Joyce, G. F. Science 323, 1229-1232 (2009)

6. Mansy, S. S. \& Szostak, J. W. Cold Spring Harb. Symp. Quant. Biol. 74, 47-54 (2009)

7. Partridge, L. \& Barton, N. H. Nature 362, 305-311 (1993)

8. Kenyon, C., Chang, J., Gensch, E., Rudner, A. \& Tabtiang, R. Nature 366 461-464 (1993)

9. Brown-Borg, H. M., Borg, K. E., Meliska, C. J. \& Bartke, A. Nature 384, 33 (1996).

10.Miller, R. A. et al. J. Gerontol. A Biol. Sci. Med. Sci. 66, 191-201 (2011) 